\title{
Cell interconnection without glueing or soldering for crystalline Si photovoltaic modules
}

\author{
Johann Summhammer a and Zahra Halavani
}

TU Wien, Institute of Atomic and Subatomic Physics, Solar Cells Group, Stadionallee 2, 1020 Vienna, Austria

Received: 30 September 2015 / Received in final form: 14 March 2016 / Accepted: 5 April 2016

Published online: 16 May 2016

(C) Summhammer and Halavani, published by EDP Sciences, 2016

\begin{abstract}
In order to maximize the power output of polycrystalline silicon PV-modules, in previous work we have already tested rectangular cells of $39 \times 156 \mathrm{~mm}$ which are overlapped along the long sides. The low current density at the cell overlap allows interconnections which need neither soldering nor glueing, but use metallic strips inserted between the cells in the overlap region. The contact is established by the pressure applied to the module during lamination and is retained by the slightly bent cells in the solidified encapsulant. Here we report on the long term stability of different contact materials and contact cross sections applied in eight modules of the $240 \mathrm{~W}$ class monitored for up to 24 months of outdoor operation and in a variety of small 5-cell modules exposed to rapid ageing tests with up to 1000 thermal cycles. Cells with three different electrode designs were tested and the contact materials were $\mathrm{Cu}, \mathrm{Ag}, \mathrm{SnPbAg}$ and Sn. Focussing especially on series resistance, fill factor and peak power, it is found that Ag-coated contact strips perform equally well and have practically the same stability as soldered cell interconnections. Due to 70-90\% savings in copper and simpler manufacturing the cost of PV-modules may thus be reduced further.
\end{abstract}

\section{Introduction}

Despite their relative maturity, solar cells and photovoltaic modules based on mono- or polycrystalline silicon still have potential for improvement, in terms of higher conversion efficiency as well as in terms of cheaper manufacturing [1]. Here we present experimental results on an interconnection method of solar cells, which permits higher power output per module area and may also lower production costs. Some preliminary results have been published before $[2,3]$. The basic idea contains two technological elements:

- First, the format of the solar cells is changed from quadratic to rectangular, the short side being much smaller than in commercial quadratic cells, and the cells are interconnected at the long sides. This leads to short electrical paths and reduces series resistance. It also reduces the linear current density to be transmitted to the next cell. This relaxes the constraints on contact resistance, which in turn allows to overlap the cells and place the interconnection in the overlap region, thereby eliminating shading from metallization and area loss from cell spacing. The advantages of the

\footnotetext{
a e-mail: summhammer@ati.ac.at
}

rectangular format are already exploited in commercially available modules with half-size cells which show a notable decrease of series resistance [4], and in sliver cells $[5,6]$, which go to an extremely small ratio of width to length.

- And second, neighbouring cells are actually overlapped, but the interconnection is not made by soldering or the innovative and more gentle methods of glueing with conductive adhesives [7-9] or any other rigid method, but relies on pure pressure between the front and rear contact areas in the overlap region of two neighbouring cells. This is similar to the technology used in NICE-modules, although there it is applied to solar cells of the usual quadratic format without overlap $[10,11]$.

The cell format used here is $39 \times 156 \mathrm{~mm}$ [12], which is one quarter of today's commercial standard of $156 \times 156 \mathrm{~mm}$. It is a compromise between the possible gains and the number of additional manufacturing steps like cell cleaving by laser and more individual cell handling. Only polycrystalline silicon solar cells were used, because of the expense and limited availability of full square $156 \times 156 \mathrm{~mm}$ monocrystalline wafers.

The optimum benefit of cells of $39 \times 156 \mathrm{~mm}$ can be obtained when their metallization pattern on the front and back side is adapted to the overlap interconnection 
method. Such special cells, which we called QuarterCells to distinguish them from quartered standard commercial cells, have been made for this investigation, but we have also employed quartered standard cells.

The reported experiments tested different kinds of overlap interconnections between the cells, all of which relied on pressure only. For this purpose so called contact strips were placed in the overlap region between two neighbouring cells. These contact strips had different cross sections and different conductive coatings. Although interconnection of metallic conductors by pressure only is a method used universally in power transmission (e.g., the cabling of buildings and machinery, sockets, switches and the multitude of plug connectors), one may doubt the reliability of such a form of interconnection for solar cells in a photovoltaic module. For instance, the contact area between the touching surfaces might decrease over time due to a relaxation of the contact force or a creep of the materials, or there might be slow oxidation or other detrimental chemical reactions of these surfaces. These effects could lead to higher series resistance and lower output power and perhaps even to an interruption of an interconnection. Therefore, the main purpose of this study was to find out how large this increase of series resistance and loss of power will be for different kinds of metallic surfaces and different shapes and thicknesses of the contact strips between the cells.

In order to obtain credible results in a reasonable time, two different sorts of modules were produced and investigated in parallel: small modules with only 5 cells each were subjected to rapid ageing in a climate chamber. And large modules with a nominal power around $240 \mathrm{~W}$, which consisted of either 246,252 or 276 cells connected in series, were mounted outdoors and their IV-curves monitored permanently for up to 28 months, at present (the experiments are still continued). These modules had operating voltages around $120 \mathrm{~V}$ and currents in the range of 2 A or more. Such high voltages of a single module have advantages for use of single-module inverters or for system-layout in building integration, as we have argued before $[2,3,11]$, but the results to be presented here will focus on the physical and technical aspects of the cell interconnection only. In the following sections we describe the technology of the modules, present the data on rapid ageing of the small modules and on the outdoor ageing of the large modules, and analyze the results in relation to the properties of the contact materials between the cells and to other module parameters. We begin with a discussion of the characteristics of the specially made QuarterCells.

\section{Concept of QuarterCells}

We introduced a first version of the concept of QuarterCells for crystalline silicon photovoltaic modules already in reference [12] and the version for overlapping of cells in reference [3], both with the aim of increasing the output power of the modules without changing the basic cell technology. The idea was initiated by the realization that the
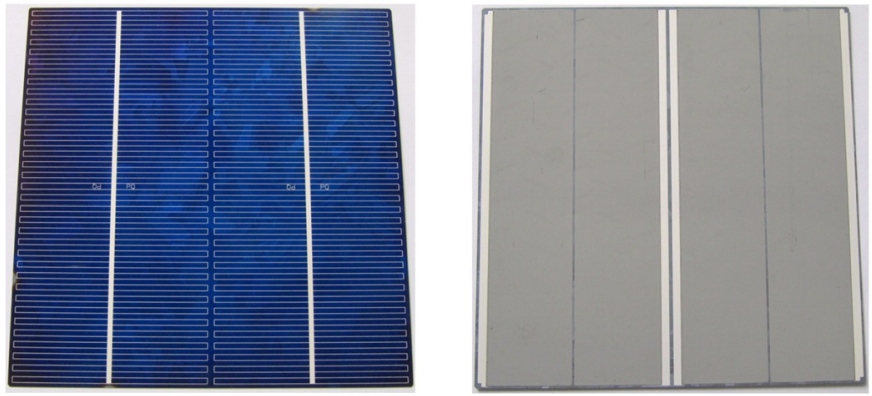

Fig. 1. Front and back side of a $156 \times 156 \mathrm{~mm}$ polycrystalline silicon solar cell to be cut into four QuarterCells. The cuts by laser are done in the three non-metallized stripes at the back, and do not go through the wafers. The final separation is done by breaking along the laser lines. This also breaks the screen printed front bus bars in two (several types of metallization have been tried, the one shown here is called QuarterCell "P").

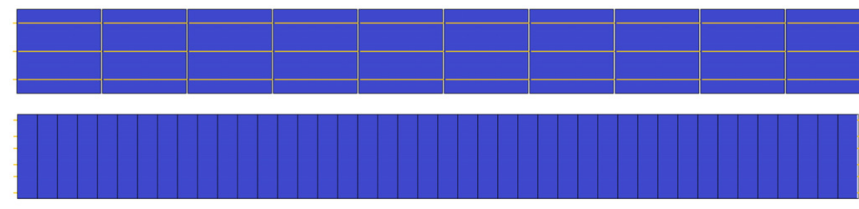

Fig. 2. Standard string of 10 cells with three busbars and string of similar length with 42 QuarterCells (overlap of cells: $2 \mathrm{~mm}$ ).

industrial standard cells of $156 \times 156 \mathrm{~mm}$ have high current and small voltage, which - even after optimizing the trade-off between minimum shading and minimum electrical series resistance - leads to appreciable optical and ohmic power losses. By slightly adapting the metallization pattern and cutting such a cell into several equal slices, and then connecting these slices in series along the long sides, it is possible to reduce these losses significantly. Especially, if these cells have a thin front bus bar and a similar rear bus bar at opposite long sides of the cell [13]. For our studies we have chosen to make four rectangular cells of $39 \times 156 \mathrm{~mm}$ out of a quadratic cell and have called them QuarterCells. A quadratic cell from which the four pieces are cut is shown in Figure 1. The QuarterCells can be connected in an overlap fashion, such that the rear bus bar of a cell lies directly on top of the front bus bar of the previous cell. A comparison of a string of ten standard cells with three busbars to a string of similar length made of QuarterCells (Fig. 2) shows that the latter can yield about $6.3 \%$ more power under standard testing conditions (STC), when normalized to the same string length. The various contributions to this gain in power and the underlying assumptions are listed in Table 1. But the interconnection of the QuarterCells must not be rigid when such strings are laminated into a module, because solar glass and silicon have different thermal expansion coefficients. In order to solve this problem, one can think of different ways of soldering or glueing to interconnect the overlapped cells. The method we investigate here is pure pressure applied to the contact areas of the cells. 
Table 1. Power losses of standard string and string with QuarterCells, relative to power theoretically obtainable from the string area if there were no metallization shading and no ohmic losses in the metallization. Normalized to same string length. Assumptions for standard string: Cell spacing $2 \mathrm{~mm}$, cross section of $\mathrm{Cu}$ solder ribbons: $0.3 \times 1.5 \mathrm{~mm}^{2}$.

\begin{tabular}{ccc}
\hline & $\begin{array}{c}\text { String with 10 } \\
\text { standard cells of } \\
156 \times 156 \mathrm{~mm} \\
\text { with three busbars }\end{array}$ & $\begin{array}{c}\text { String with 42 } \\
\text { QuarterCells of } \\
156 \times 39 \mathrm{~mm}, \\
\text { overlap 2 mm }\end{array}$ \\
\hline Area loss by bus bars & $2.9 \%$ & $0.0 \%$ \\
Area loss by cell spacing & $1.3 \%$ & $0.0 \%$ \\
Ohmic loss in bus ribbons at STC & $2.3 \%$ & $\sim 0.0 \%$ \\
Ohmic and area loss because of & n.a. & $0.2 \%$ \\
additional metal fingers & & $0.2 \%$ \\
TOTAL & $6.5 \%$ & \\
\hline
\end{tabular}
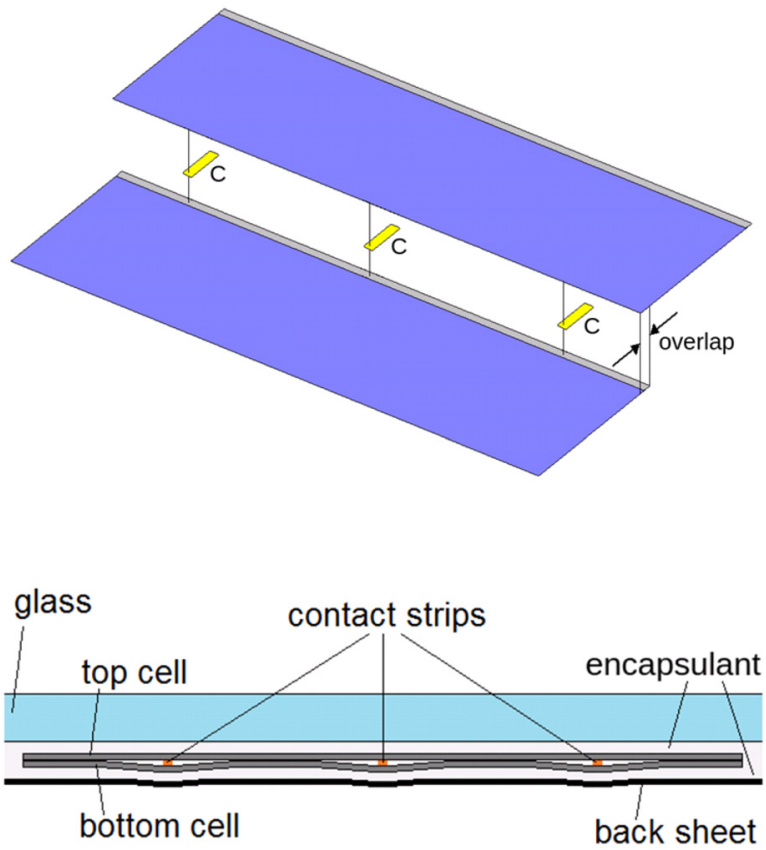

Fig. 3. Top: scheme of contacting two QuarterCells by overlap and with contact strips. Bottom: cross section through finished module at the overlap of two cells. In the overlap region the cells bend slightly around the contact strips.

\section{Tests in this study}

The technology investigated here is a method of interconnecting such overlapped cells by pressure only. The essential elements are small metallic contact strips which, in the overlap region, are placed on the front bus bar of the lower cell and which touch the rear bus bar of the next cell when it is placed on top (Fig. 3, top). The force for good contact is built up during lamination into a module. It is important that the module is of the type glass encapsulant - cells - encapsulant - back sheet. The pressure exerted on the elastic back sheet during lamination bends the cells slightly around the contact strips, and these bends become permanent, if the lamination pressure is kept on during the cooling phase of the lamination until the encapsulant has sufficiently hardened. The permanent bends of the cells create sufficient contact force to ensure good electrical connection between the cells (Fig. 3, bottom). Since there is no rigid connection, the cells can still slide against each other, and in this manner the string will follow the thermal expansion or contraction of the solar glass during changes in temperature, or when the module is exposed to mechanical loads, with little or no mechanical stress on the solar cells themselves.

The concept of connecting cells in this manner is not restricted to the type of QuarterCells shown in Figures 1 and 3 , but can also be applied to normal cells, which are cut into four (or any other number) equal slices perpendicular to the bus bars and then connected in an overlap fashion. This has also been investigated in this work.

In order to assess the feasibility of this type of interconnection, a number of small and large modules were produced. Since this was an explorative study, and as no similar study seems to have been done before, only general information on the functioning of electrical contacts could be relied on. For instance, a mechanical electrical connection is usually established through many small holes in the oxide layers between the two contacting surfaces and the number of these holes increases with contact force [14]. This suggested to use malleable metals and to create a rather strong curvature of the cells. Therefore the various small and large modules differed by the materials used in the contact strips, their width and thickness, as well as by the number of contact strips between two cells, and by the type of cells used. In several cases only one module with a specific material, width and thickness of the contact strips was made. This was based on the reasoning that, since there are many identical contact strips in a module, already a single module's behaviour should provide valuable information on that type of contact strip.

For all modules, except one small module, the encapsulant was EVA. The small modules consisted of 5 QuarterCells each, or of 5 slices of $39 \times 156 \mathrm{~mm}$ cut from standard cells perpendicular to their busbars. The large modules were of the $240 \mathrm{~W}$ class, and consisted each of six strings, a string containing between 41 and 46 QuarterCells (or quarters of cells cut from standard cells). In each of the large modules, all strings were connected in series, which resulted in operating voltages around $120 \mathrm{~V}$. The small modules were subjected to rapid ageing tests by temperature cycling. After about every 50 cycles their IV-curves 
Table 2. Cell types and contact strips used in the small modules. The first column shows pictures of the front and back side of the cells used. Symbols: $d$, thickness of the coating of the contact strips. $T, W$, thickness and width of the contact strips, respectively. $N$, how many contact strips were used between two neighbouring cells. $R_{\mathrm{s}, \text { in }}$, initial series resistance, determined from a fit of the theoretical IV-curve of the one-diode model to the data of the IV curves measured right after production of the modules. *, "tinned iron", a core of Fe with a thin layer of Sn, whose thickness was below $1 \mu \mathrm{m}$.

\begin{tabular}{|c|c|c|c|c|c|c|c|}
\hline \multirow[b]{2}{*}{ Cell type } & \multirow{2}{*}{$\begin{array}{c}\text { Module } \\
\text { name }\end{array}$} & \multicolumn{4}{|c|}{ Contact strips } & \multirow{2}{*}{$\begin{array}{l}R_{\mathrm{s}, \mathrm{in}} \\
{[\mathrm{m} \Omega]}\end{array}$} & \multirow{2}{*}{$\begin{array}{c}\text { Number of } \\
\text { temperature } \\
\text { cycles }\end{array}$} \\
\hline & & \multicolumn{2}{|c|}{ Coating $d[\mu \mathrm{m}]$} & $\begin{array}{c}T \times W \\
{[\mathrm{~mm}]}\end{array}$ & $N$ & & \\
\hline \multirow[t]{4}{*}{ Standard } & S1 & $\mathrm{SnPbAg}$ & 15 & $0.15 \times 2.5$ & 2 & 193 & 760 \\
\hline & $\mathrm{S} 2$ & $\mathrm{SnPbAg}$ & 15 & $0.20 \times 2.0$ & 2 & 80 & 760 \\
\hline & S3 & $\mathrm{Cu}$ & & $0.20 \times 2.5$ & 2 & 165 & 796 \\
\hline & $\mathrm{S} 4$ & $\mathrm{Ag}$ & $\sim 1$ & $0.30 \times 2.2$ & 2 & 95 & 546 \\
\hline \multirow[t]{5}{*}{ QuarterCell K } & $\overline{\mathrm{K} 1}$ & $\mathrm{Ag}$ & 6.5 & $0.19 \times 5.0$ & 4 & 114 & 1006 \\
\hline & K2 & $\mathrm{Ag}$ & 6.5 & $0.19 \times 5.0$ & 4 & 92 & 1006 \\
\hline & K3 & $\mathrm{Ag}$ & 6.5 & $0.25 \times 5.0$ & 3 & 113 & 493 \\
\hline & $\mathrm{K} 4$ & $\mathrm{Ag}$ & $\sim 1$ & $0.30 \times 2.2$ & 3 & 296 & 546 \\
\hline & K5 & $\mathrm{Cu}$ & & $0.20 \times 5.0$ & 3 & 226 & 796 \\
\hline \multirow[t]{6}{*}{ QuarterCell P } & $\mathrm{P} 1$ & $\mathrm{SnPbAg}$ & 6.5 & $0.05 \times 3.5$ & 7 & 65 & 685 \\
\hline & $\mathrm{P} 2$ & $\mathrm{SnPbAg}$ & 6.5 & $0.05 \times 3.5$ & 7 & 66 & 685 \\
\hline & P3 & $\mathrm{Ag}$ & 6.5 & $0.05 \times 5.0$ & 7 & 44 & 685 \\
\hline & P4 & $\mathrm{Ag}$ & 6.5 & $0.05 \times 5.0$ & 7 & 54 & 685 \\
\hline & P5 & $\mathrm{Ag}$ & 6.5 & $0.19 \times 2.5$ & 3 & 36 & 796 \\
\hline & $\mathrm{P} 6$ & $\mathrm{Sn}$ on $\mathrm{Fe}^{*}$ & $<1$ & $0.20 \times 2.0$ & 3 & 129 & 350 \\
\hline
\end{tabular}

were recorded under STC. Although rapid ageing in the laboratory does not necessarily show the same degradation mechanisms as real outdoor wheathering, they are usually a fast indicator of possible failure modes [15]. The large modules were put into outdoor operation and IV-curves were recorded every two minutes.

\section{Rapid ageing tests of small modules}

An overview of the investigated small modules is shown in Table 2. As can be seen there, three different kinds of cells were used. One type were quartered standard cells with two bus bars. The other two types were two variations of QuarterCells. One was the QuarterCell of type P, already shown in Figure 1. The other one was called QuarterCell of type K. Its front metallization was the same as that of type $\mathrm{P}$, but at the back side the bus bars consisted of 6 pads of $2 \times 17 \mathrm{~mm}^{2}$ and started only $3 \mathrm{~mm}$ from a long edge (see the pictures in Tab. 2). All cells were from p-doped polycrystalline silicon of a thickness between 220 and $240 \mu \mathrm{m}$ with an n-doped emitter and the metallization was made by screen printing. They were produced by the company Falconcell (operations ceased in 2013). The contact strips were made from different foils, which usually consisted of a core of copper plus a coating (except module P6, see Tab. 2). Since the coating is the relevant material, its thickness is listed separately in Table 2. The only type of contact strips which had no coating were the pure copper contact strips. More details of the contact strips will be given in the presentation of the individual modules. The front glass of the modules was normal $2 \mathrm{~mm}$ float glass. As encapsulant two sheets of $0.5 \mathrm{~mm}$ thick EVA were used, one on each side of the cell string, except for module S4, where the silicone-based Tectosil by Wacker was used. Further tests with Tectosil showed that, since it becomes very liquid during lamination, either the pressure is not fully conveyed to the cells or the contact strips obtain a thin insulating film, and no reliable cell interconnections could be produced. Therefore no additional modules with Tectosil were made. The back sheet of all modules was $0.17 \mathrm{~mm}$ thick Tedlar and usually black, in some modules it was transparent. The lamination pressure was 820 mbar, except for modules P1 and P3, where it was only 620 mbar.

\subsection{Small modules with quartered standard cells}

With this type of cell four small modules were investigated (S1-S4 in Tab. 2). The overlap of the cells was $2 \mathrm{~mm}$. The contact strips were placed along the bus bars and were allowed to stick out on the front side of the cells by 2 to $3 \mathrm{~mm}$, as can be seen in Figure 4b. The length of the contact strips was between 12 and $20 \mathrm{~mm}$ (depending on the material and form used) so that there was usually much more contact area with the rear bus bars than with the front bus bars. The connections at the ends of the modules were done by soldering $\mathrm{SnPbAg}$-coated solar ribbon with copper core to the first and the last cell. Since there was no mechanical connection between the cells, as well as between the cells and the contact strips, they were held together by high temperature adhesive tape (PPI $1040 \mathrm{~W}$, thickness $50 \mu \mathrm{m}$ ) as is visible in Figure 4c. Module S1 had contact strips made from ordinary solar soldering ribbon with copper core and $\mathrm{SnPbAg}$-coating, but they were not soldered to the cells. Module S2 also used contact strips from such ribbon but of different cross section. Module S3 used pure copper strips and module S4 used copper ribbon with a thin galvanic layer of silver (supplied by the company Ulbrich of Austria). 


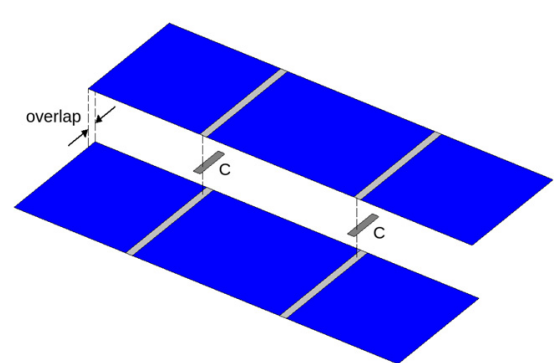

(a)

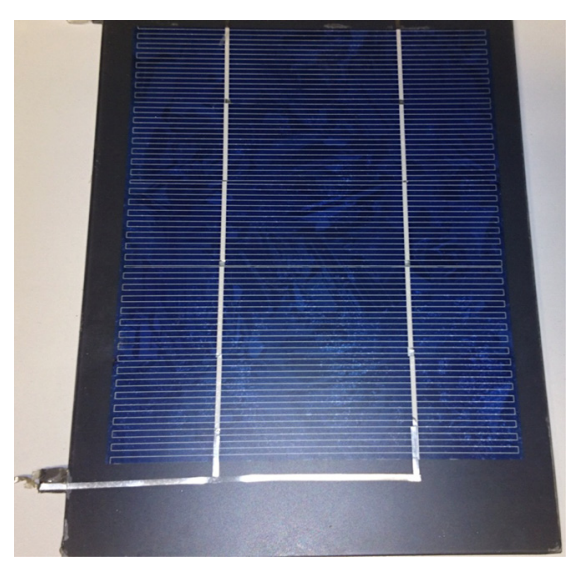

(b)

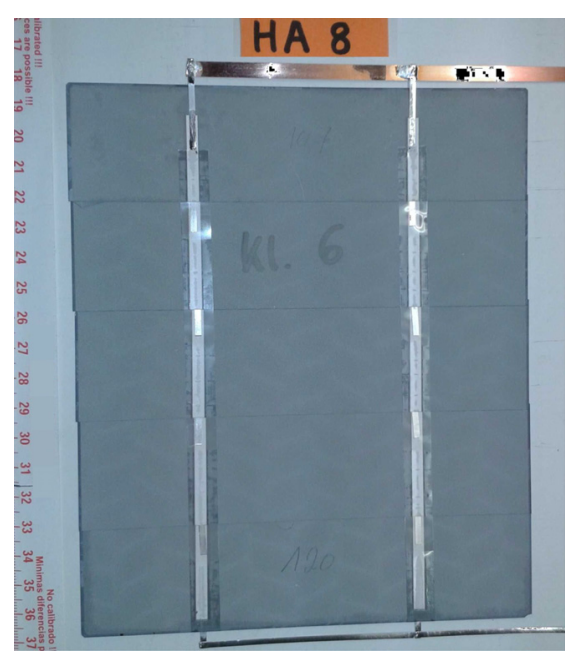

(c)

Fig. 4. (a) Interconnection scheme used in all small modules with quartered standard solar cells (S1-S4). (b) Front side of module S2. (c) Back side of module S4 before lamination.

\subsection{Small modules with QuarterCells K}

Here, five modules were investigated (K1-K5). Modules $\mathrm{K} 1$ and $\mathrm{K} 2$ were made in identical manner. Since the QuarterCells K had their back side bus pads relatively far from the edge (see photograph in Tab. 2) the cell overlap in these two modules was $5 \mathrm{~mm}$, so that the front bus bar of one cell was directly under the back side bus bar of the next cell (Fig. 5a). The contact strips were made from silver coated copper ribbon with a cross section of $5.00 \times 0.05 \mathrm{~mm}^{2}$, the thickness already including $6.5 \mu \mathrm{m}$ of silver on each side (supplied by Schlenk Metallfolien). Pieces of about $30 \mathrm{~mm}$ length were folded once to obtain strips of $15 \mathrm{~mm}$ length. These were then folded again at $2 \mathrm{~mm}$ from the bent end to obtain an end section of $0.19 \mathrm{~mm}$ thickness (after pressing), a length of $2 \mathrm{~mm}$ and a width of $5 \mathrm{~mm}$. These served as the actual contact pieces between the cells. The rest of the length of these strips was needed to attach these pieces to the back side of the cells with adhesive tape. Figure 5a shows the connection scheme and Figure $5 \mathrm{~b}$ the back side of one of these modules before lamination.

Modules K3, K4 and K5 used a cell overlap of only $2 \mathrm{~mm}$. Therefore front and rear bus bars of neighbouring cells were not on top of each other. In the finished module this would lead to pressure of the contact strips onto the front bus bars, but not on the rear bus pads. In order to get contact pressure there, too, the contact strips received an embossing at a position which lay exactly on the rear bus pads as shown in Figure 5c. Since, at the back side of the cells, the contact strips were covered with adhesive tape, after lamination this tape together with the EVA encapsulant and the back sheet had a small deformation rising above the smooth surface of the module's back side and this exerted a force on the contact strip and kept it pressed onto the bus pads. This method is a deviation from the original idea of forming contact by placing front and rear bus bars of two neighbouring cells right on top of each other with a contact strip in between. However, it was tried out, because this option offered the possibility to interconnect the QuarterCells $\mathrm{K}$ with only $2 \mathrm{~mm}$ overlap instead of $5 \mathrm{~mm}$ (the QuarterCells of type $\mathrm{K}$ were originally developed for soldered cell interconnections similar to the US-patents [13], in a project with company Kioto Photovoltaics).

The contact strips of K3 were made from the same silver coated copper ribbon as in modules $\mathrm{K} 1$ and $\mathrm{K} 2$, but the ribbon was folded to obtain five-fold thickness, such that the dimensions of the contact strips were $0.25 \times 5 \times$ $12 \mathrm{~mm}(T \times W \times L)$ after pressing, and then the embossing was made. Module K4 used copper contact strips with a thin galvanic layer of silver (the same silver coated copper ribbon as in module $\mathrm{S} 4$ was used). Module K5 used contact strips made from pure copper ribbon.

\subsection{Small modules with QuarterCells P}

The back side bus bar of these cells was right at the edge of a long side and was uninterrupted (see photograph in Tab. 2). This permitted the special kind of interconnection shown in Figure 6a. It was applied in the modules P1, P2, P3 and P4. The overlap of the cells was $2 \mathrm{~mm}$.

The special connector consisted of two strips of adhesive tape, which were laid on top of each other with the non-sticky sides facing each other. Then V-shaped pieces of contact ribbon were wrapped around them and stuck to the tapes. This connector was then first pressed onto the front bus bar of one cell and thus stuck to it. Then the 


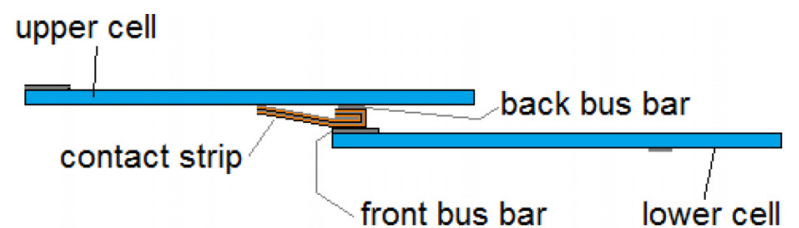

(a)

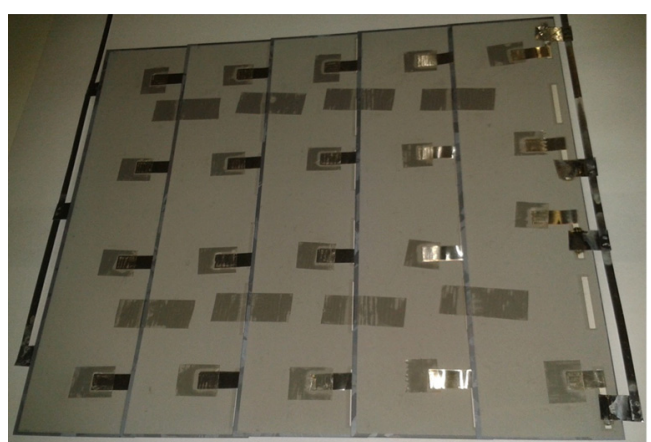

(b)

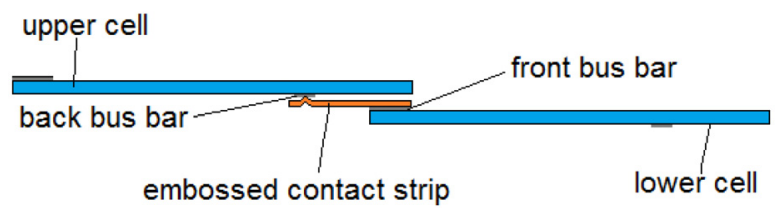

(c)

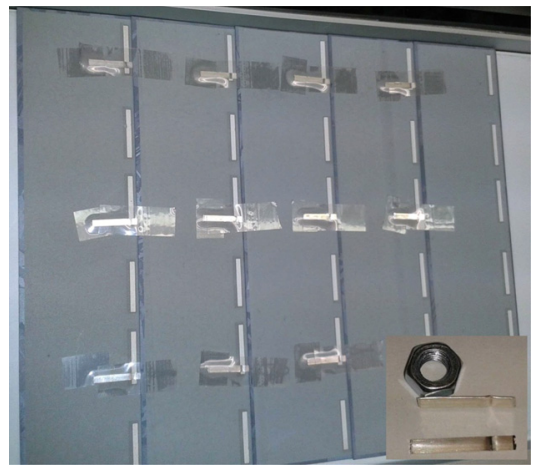

(d)

Fig. 5. (a) Side view of connection scheme of two cells as used for modules K1 and K2 (not to scale). (b) Back side of module $\mathrm{K} 1$ before lamination. At the ends of the module solar ribbon was soldered to the cells. (c) Side view of connection scheme of two cells as used for modules K3, K4 and K5 (not to scale). (d) Back side of module K4 before lamination. The insert in the lower right corner shows contact strips with embossing.

second cell was laid on top, and also stuck to the connector. In this manner, the cells were already electrically connected and held in place, but they could still slide against each other a little bit, because the bends in the V-shaped contact strips would allow a little motion. Once the cells were embedded in the module, the cells were slightly bent around the contact strips, which caused additional contact force. As will be seen, this type of connection showed the lowest series resistance and suffered virtually no deterioration in hundreds of temperature cycles. For modules P1 and P2 the contact strips were made from solar ribbon of $50 \mu \mathrm{m}$ thickness, with a $37 \mu \mathrm{m}$ copper core and $6.5 \mu \mathrm{m}$ $\mathrm{SnPbAg}$ coating on each side. The width of the ribbon was $3.5 \mathrm{~mm}$. (Ribbon supplied by Schlenk Metallfolien.) For modules P3 and P4 the same Ag-coated copper ribbon was used as in other modules before (e.g. K1, K2), but it was not folded, and its thickness was thus only $50 \mu \mathrm{m}$.

The modules P5 and P6 used straight contact strips as shown in Figure 6c. Those of P5 were Ag-coated. Those of $\mathrm{P} 6$ were made from tinned iron, the thickness of the Sn coating was not determined exactly but was below $1 \mu \mathrm{m}$.

\subsection{Results of thermal cycling of small modules}

The rapid ageing tests were done by repeated thermal cycling. The available climate chamber permitted heating to about $90{ }^{\circ} \mathrm{C}$ and cooling down to $-26{ }^{\circ} \mathrm{C}$. The first 400 cycles were done between $85{ }^{\circ} \mathrm{C}$ and $-26^{\circ} \mathrm{C}$. Then it was changed to the range $87^{\circ} \mathrm{C}$ to $-24^{\circ} \mathrm{C}$. The temperature was monitored in four different positions in the chamber. With a fan it was held homogeneous to within +$0.7^{\circ} \mathrm{C}$. One cycle lasted a little over $8 \mathrm{~h}$. The rise and fall of temperature were exponential, the operational modes of the climate chamber being either constant heating or constant cooling. The modules were open circuited during the cycles. After about every 50 cycles the IV-curves of the modules were recorded under STC. Since the modules were added to the climate chamber as soon as they were produced, not all modules have undergone the same number of cycles to date. The module with the smallest number is $\mathrm{P} 6$ with 350 cycles.

There are several ageing effects to be expected. Aside from deficiencies of the embedding material, like diffusion of water vapor [16] or yellowing of the EVA [17], one could expect an increase in series resistance of the cells due to abrasion or slow oxidation or other chemical reactions of the contact strips. This might go as far as complete loss of electrical contact between cells. At the bends of the cells around the contact strips microcracks might develop, which could lead to smaller parallel resistance of the cells and module [18]. Cells might also obtain macroscopic cracks in these regions, which could reduce the short circuit current [19]. The analysis of the IV-curves revealed, however, that all effects are negligible, except for an increase in series resistance which strongly depends on the material of the contact strips. The increase of series resistance entails a decrease in fill factor and thus a decrease of power output. Figures 7 and 8 show this decrease for the three different types of cells. In the following the ageing effects will be discussed separately for each coating material of the contact strips, because this is the dominant determining factor, independent of cell type.

SnPbAg: The strongest deterioration is observed on modules with $\mathrm{SnPbAg}$-coated contact strips which were 


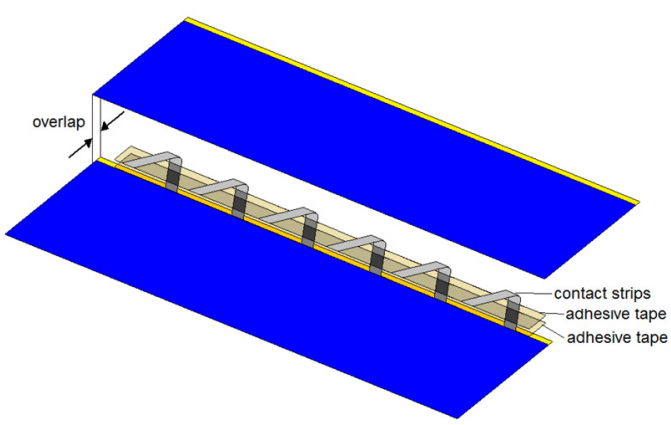

(a)

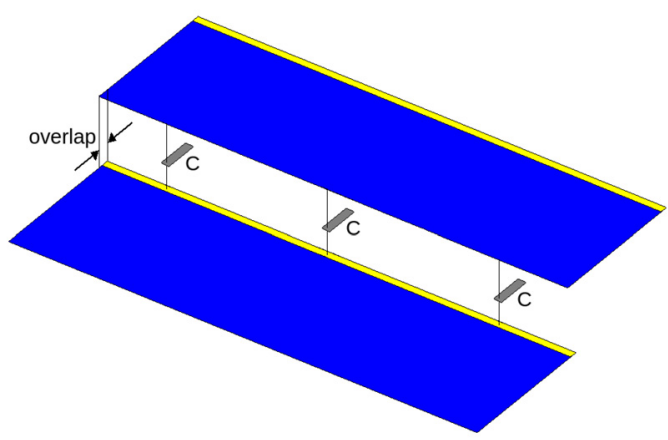

(b)

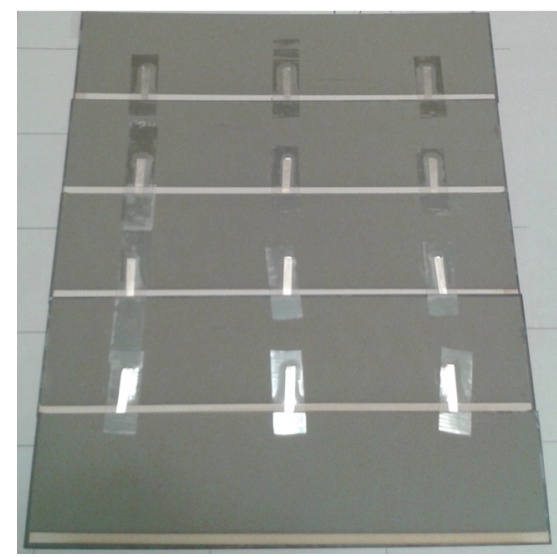

(c)

Fig. 6. (a) Connection scheme for modules P1, P2, P3, P4. (b) Connection scheme for modules P5 and P6. (c) Back side of module P5 before lamination.

made from ordinary solar ribbon. This kind of contact strips was used for two modules with quartered standard cells (S1, S2) and for two modules with QuarterCells P $(\mathrm{P} 1, \mathrm{P} 2)$. In all four modules the power loss reaches $5 \%$ or more after only around 100 cycles, and from then on it deteriorates fast and in an erratic manner with occasional recovery. This is probably caused by abrasions of the relatively soft $\mathrm{SnPbAg}$ (Brinell hardness 16-17 MPa) on the harder surfaces of the screen printed bus bars when the cells slide against each other (the busbars are mainly of sintered silver particles, Brinell hardness 206-250 MPa). The repeated contractions and expansions of the front
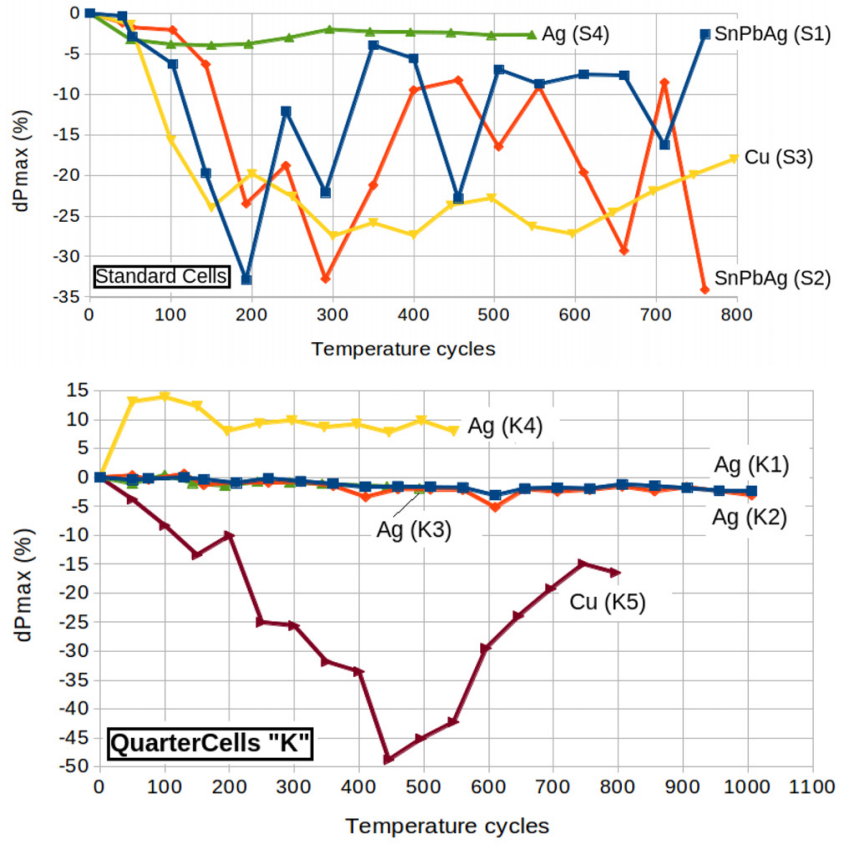

Fig. 7. Relative decrease of power output (dPmax) under STC for small modules as a function of the number of temperature cycles. Top: modules with quartered standard cells. Bottom: modules with QuarterCells K. The labels indicate the coating of the contact strips and the name of the module.

glass of the module are enforced on the cells, because the glass is much thicker than the cells, and each cell can be considered attached to the glass at its midpoint due to the encapsulant. This model has been found to agree reasonably well with observed cell displacements during thermal cycling [20,21]. To verify the existence of scratches in the $\mathrm{SnPbAg}$-layer, after the thermal cycles module S1 has been opened at two different positions to take out the contact strips and inspect them with a microscope (Fig. 9). In Figures $9 \mathrm{~b}$ and $9 \mathrm{c}$ one clearly observes scratches parallel to the length of the strips where the edge of the top cell pressed onto them. Further to the right, in the $2 \mathrm{~mm}$ long overlap zone, one also finds scratches in the same direction. Since they are not visible in the whole overlap zone, one may infer that the contact strips were not pressed flat completely during the lamination process and that, in particular, the approximately $0.15 \mathrm{~mm}$ thick copper core of these strips was too hard. With a thermal expansion coefficient of the used plate glass of $9 \times 10^{-6}$ [22] and of $2.6 \times 10^{-6}$ for silicon [23] a theoretical length of the scratches of about $25 \mu \mathrm{m}$ could be expected, caused by the temperature range $-24^{\circ} \mathrm{C}$ to $+87^{\circ} \mathrm{C}$. However, the scratches tend to be up to 2 or 3 times as long. We attribute this to the much larger expansion coefficient of the Tedlar back sheet $\left(28 \times 10^{-6}[24]\right)$ and a similarly large expansion coefficient, but also a material transition below about $0{ }^{\circ} \mathrm{C}$ of EVA [25], which caused actual bending and re-straightening of these small modules during the thermal cycles. 

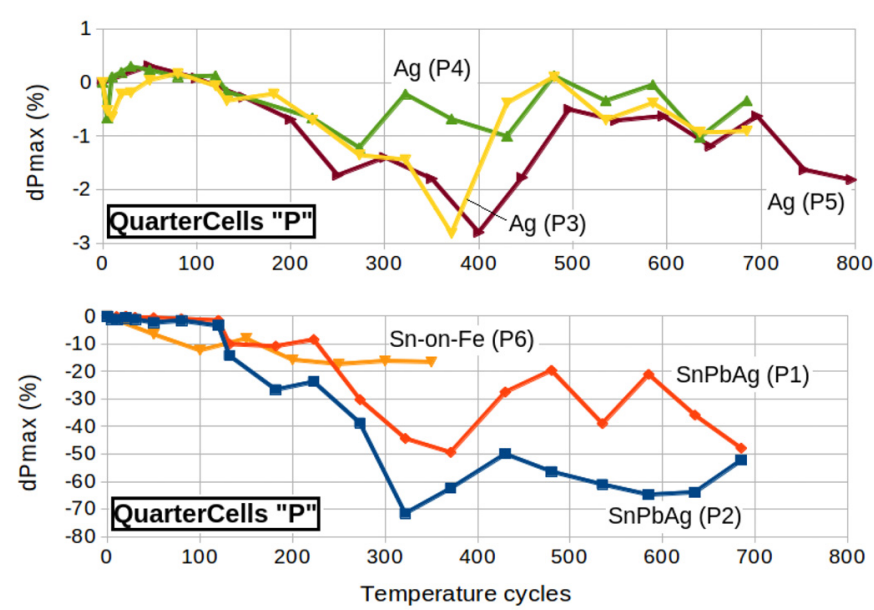

Fig. 8. Relative decrease of power output (dPmax) under STC for small modules made from QuarterCells P as a function of the number of temperature cycles. Top: modules with Ag-coated contact strips. Bottom: modules with other contact strips. The labels indicate the coating of the contact strips and the name of the module. Note that the top graph has a much narrower range of dPmax.

In principle, the contact resistance between the contact strips and the contacted areas of the cells should decrease with pressure [14]. But a relationship of the power loss with stronger contact force is not apparent, as module $\mathrm{S} 2$ tended to deteriorate faster than module S1, although it had thicker contact strips and therefore more strongly bent cells resulting in higher contact force. Similarly, module P2 performed worse than the identical module P1, although the former was laminated with 820 mbar and the latter with only 620 mbar. Here it must be mentioned, however, that the pressure during lamination may not be so important, as long as it is sufficiently high to bend the cells around the contact strips. Of more relevance may be the high pressure which the cells should experience from the contraction and hardening of EVA in the cool periods of the thermal cycles $[26,27]$. As evidenced by the scratches, the rough surface of the bus bars causes permanent indentations on the $\mathrm{SnPbAg}$ coating, and these could become so deep, that in the relaxed state of EVA at STC-temperatures and above the $\mathrm{SnPgAg}$ coating formed only loose contact to the cells and actually decreased the contacted area.

Copper: Pure copper contact strips were used in module S3 with quartered standard cells and in module K5 with QuarterCells K. Since copper has a higher hardness than silver or SnPbAg (Brinell hardness 235-878 MPa) one could expect that these contact strips adapt less to the rough surface of the sintered bus bars during lamination, resulting in smaller contact area and higher initial series resistance. This is true for K5, but for S3 only in tendency, compared to the similar modules with $\mathrm{SnPbAg}, \mathrm{S} 1$ and $\mathrm{S} 2$. Then, during thermal cycling, the two modules show a fast decrease of power, but it is less erratic than with modules with $\mathrm{SnPbAg}$-coated contact strips. One cause may be permanent indentations, in this case into the softer silver

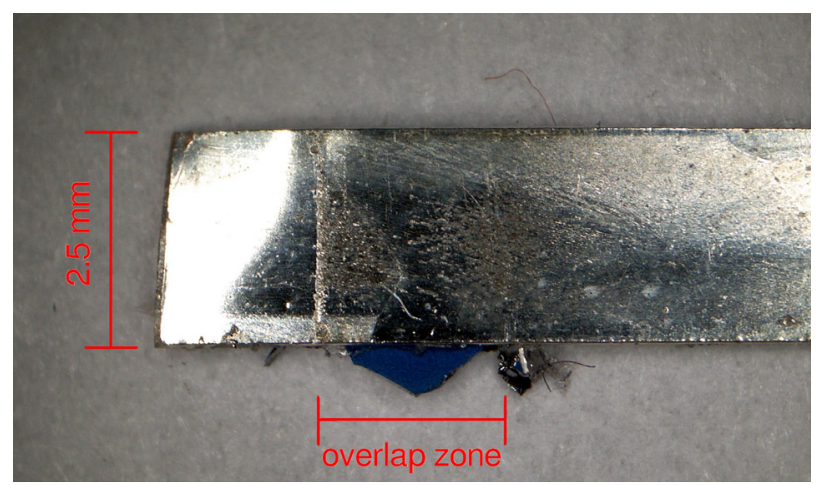

(a)

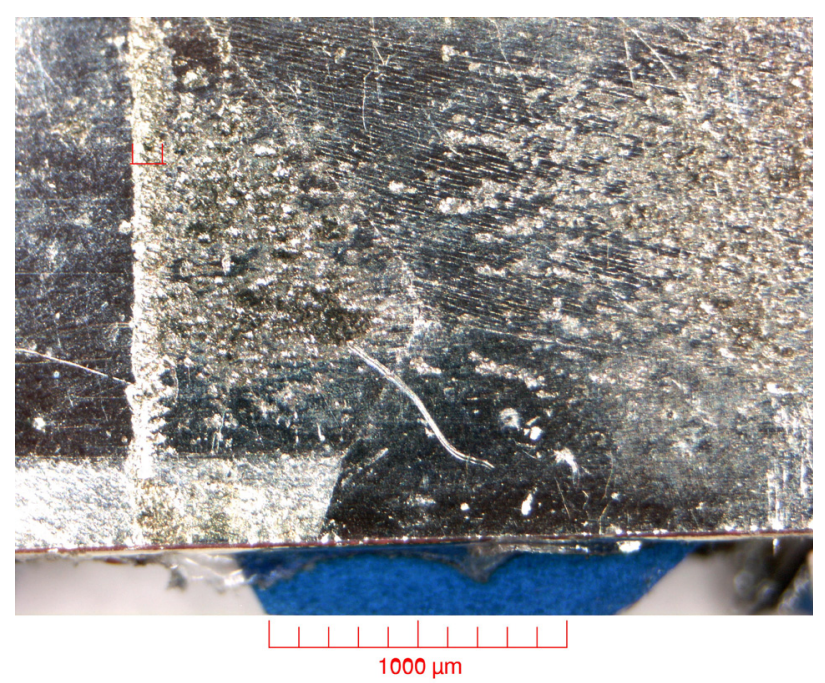

(b)

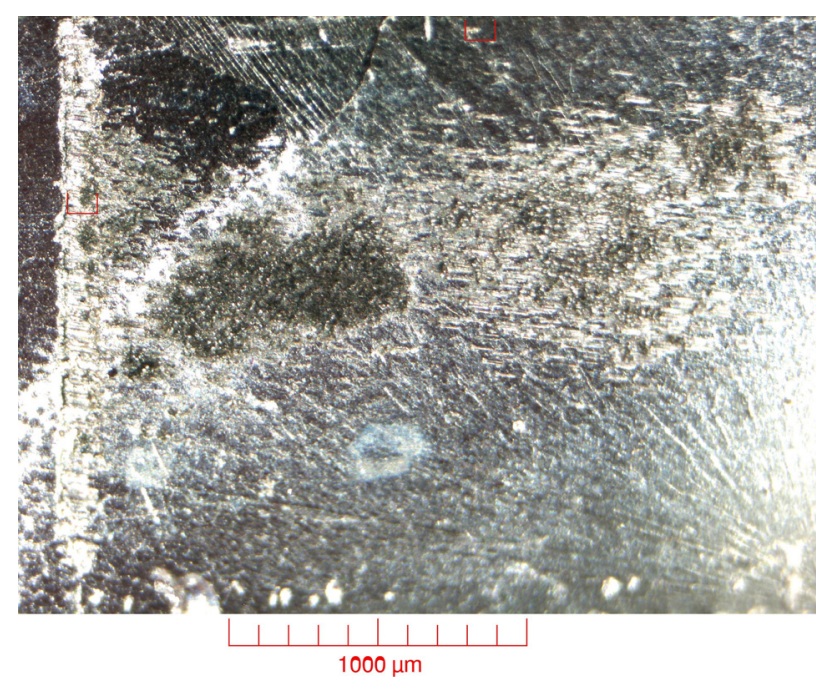

(c)

Fig. 9. (a) Top view of a contact strip from module S1 consisting of $0.15 \mathrm{~mm} \mathrm{Cu}$-core with $15 \mu \mathrm{m} \mathrm{SnPbAg}$ solder coating. The region where it was pressed on by the back side of the cell lying on it starts about $2 \mathrm{~mm}$ from the left side. Scratches are visible. (b) Enlarged view of the contact region with scratches. (c) Enlarged top view of another contact strip, with visible scratches. 

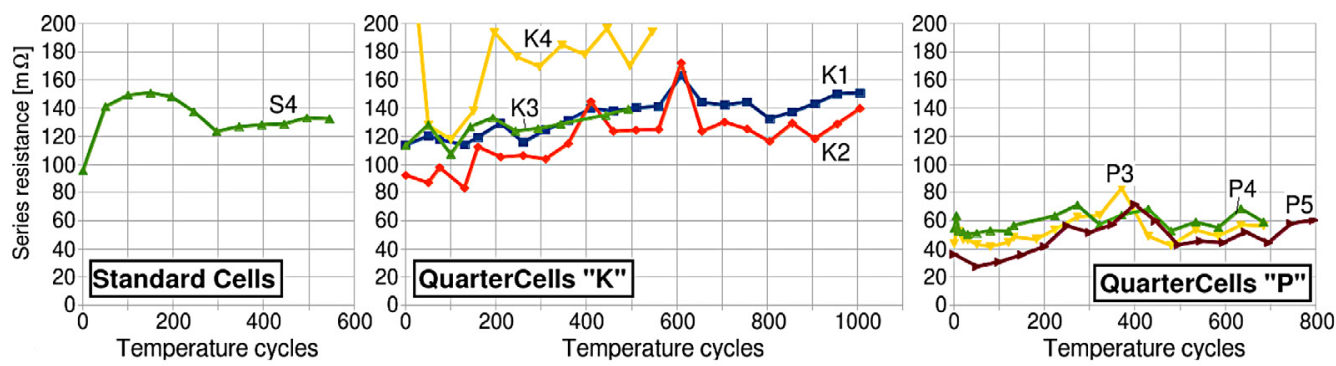

Fig. 10. Series resistance of all small modules with Ag-coated contact strips as a function of the number of temperature cycles. The contact strips of modules S4 and K4 were thicker and had thinner Ag-coating than all the others (see Tab. 2). Modules P3 and P4 had the connector with the largest contact area, shown in Figure 6a.

particles of the bus bars, during the cold stages of the thermal cycles, which then resulted in areas of no contact at ambient temperatures. Another may be oxidation, as $\mathrm{Cu}$ may react with acidic by-products in EVA [28]. However, current flow through oxide layers is unlikely. Both $\mathrm{CuO}$, which forms first, and $\mathrm{Cu}_{2} \mathrm{O}$, which makes up the bulk of the oxyde layer, are semiconductors [29], and the conductivity of $\mathrm{Cu}_{2} \mathrm{O}$ is found in the range of 120 [30] to several thousand [31] $\Omega \mathrm{cm}$. Assuming $1000 \Omega \mathrm{cm}$, an oxide layer as thin as $10 \mathrm{~nm}$, and a contact cross section as large as $4 \mathrm{~mm}^{2}$ would result in a resistance of $250 \mathrm{~m} \Omega$ at one interface. This is too high to account for the observed increases in series resistance, so that direct contact of the metals through asperities in the oxide layer must be the path of conductance [14]. With module K5 the very strong decrease of almost $50 \%$ in output power and subsequent steady increase to $16 \%$ after 800 cycles may have to do with the fact that this was one of the modules where the contact force on the back side of the cells only originated in the bends in the adhesive tape and the back sheet and the probably inhomogeneous distribution of EVA. The repeated softening and hardening of these materials may have led to additional rubbing of the $\mathrm{Cu}$ contact strips on the bus pads, which must have cured the contact properties by creating more asperities in the oxide layers. A small effect of curing seems to be present in S3, too. So, in both cases a change of the elastic properties of EVA may have played a role $[32,33]$.

Sn on Fe: There was only one module with contact strips made from iron coated with Sn (P6). The choice of this material was based on long term corrosion resistance of Sn [34]. Although data of only 350 cycles are available until now, one observes a slower deterioration than with pure $\mathrm{Cu}$ contact strips or with $\mathrm{SnPbAg}$ coated contacts strips. Also, the deterioration is less erratic than with these materials. Nevertheless, it is strong enough to exclude this type of contact strips from further considerations.

Silver: The eight modules which used Ag-coated contact strips show the smallest loss of power, and it is very similar for all three kinds of cells. Since these were the best performing small modules, the evolution of their series resistance values is also shown in Figure 10. Interestingly, in some of these modules (P3, P4, P5, K1, K4) the power actually increases during the first 100 thermal cycles and from then on decreases only slightly. The series resistance exhibits a corresponding inverse tendency. This behavior may be due to the adaptation of the Agcoating of the contact strips to the morphology of the screen printed bus bars and may have led to increased direct metal-metal contact area during the first cycles. The effect is particularly strong for module $\mathrm{K} 4$, which used QuarterCells K and was one of those, where the contact pressure on the rear bus bars was only caused by the elasticity of the adhesive tape, the EVA, and the back sheet (see Fig. 5c). The thermal cycles might have lead to additional shrinkage of the EVA $[27,33]$, thereby increasing contact force. Aside from these mechanical aspects, the chemical properties of silver also favor a good performance of modules with Ag-coated contact strips. Silver does not react directly with $\mathrm{O}_{2}$, but with atomic oxygen, thus slowing down the growth of a semiconducting $\mathrm{Ag}_{2} \mathrm{O}$ layer to only some $1.2 \mathrm{~nm}$ in 4 to 5 hours in ambient air, while during the same time $\mathrm{Cu}$ would develop a layer of $\mathrm{Cu}_{2} \mathrm{O}$ four times as thick [35]. Moreover, the electrical resistivity of $\mathrm{Ag}_{2} \mathrm{O}$ is only in the range of $4.2 \times 10^{-4}$ to $5.2 \times 10^{-3} \Omega \mathrm{cm}[36]$. This is at least a factor of $10^{-5}$ less than the value for $\mathrm{Cu}_{2} \mathrm{O}$ mentioned before. In air, silver also reacts with sulfur-containing molecules to a tarnish of semiconducting $\mathrm{Ag}_{2} \mathrm{~S}$ [37], which has a room temperature resistivity around $10 \Omega \mathrm{cm}$, and which decreases with increasing film thickness [38]. This resistivity is still a factor of 0.1 to 0.01 less than that of $\mathrm{Cu}_{2} \mathrm{O}$. Although one can assume that, here too, the electrical conduction from contact strips to busses proceeds mainly through small holes in the oxide and sulfide layers where metal-metal contact is established [14], the good conductivity of $\mathrm{Ag}_{2} \mathrm{O}$ and $\mathrm{Ag}_{2} \mathrm{~S}$ is very advantageous.

When asking which type of cells and which kind of interconnection performed best, the answer clearly is QuarterCells $\mathrm{P}$ with the special interconnector shown in Figure $6 \mathrm{a}$ and with contact strips with Ag-coating. The initial values of series resistance of modules with this type of connector are distinctly among the lowest of all modules (P3, P4, see Fig. 10). As can be seen in Table 2, this was also the case for the two modules with this type of connector whose contact ribbon was coated by $\mathrm{SnPbAg}(\mathrm{P} 1, \mathrm{P} 2)$. The most likely explanation is that this type of connector offers the largest contact area. Incidentally, it also leads to the smallest bending of the cells, and this might reduce the 


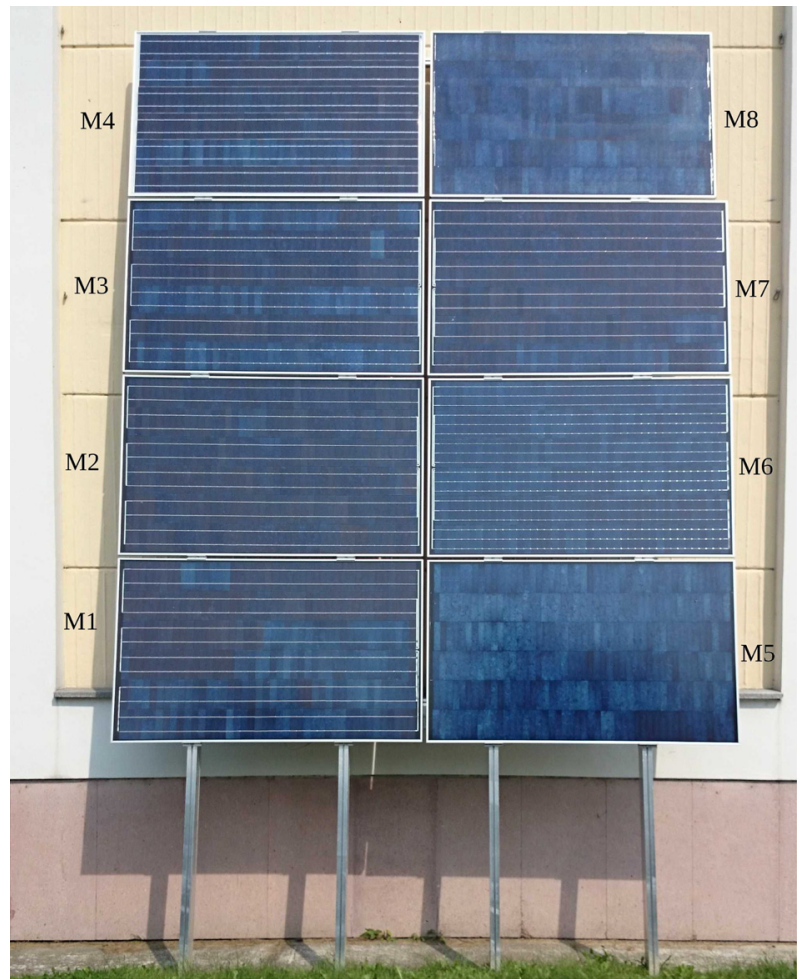

Fig. 11. Modules mounted for outdoor monitoring at south west facade of Institute of Atomic and Subatomic Physics at TU Wien. The outer dimensions of modules M1-M7 are $1629 \times$ $982 \mathrm{~mm}$, those of M8 are $1564 \times 982 \mathrm{~mm}$.

contact force. But with this connector the contact force to the busbars is to some degree also generated by the adhesive tape, which meanders up and down, and its tendency to straighten itself creates additional contact force. There is one module with Ag-coated contacts (P5), which had a still lower initial series resistance and did not have this special connector, although the difference is in the range of the reproducibility of the used method of extracting the series resistance from the IV-curve. This module used only three contact strips (Fig. 6c). What may certainly have helped to reduce the series resistance of this module is that, in the regions between the contact strips, the front and rear busbars of any two overlapped cells touched each other over several centimeters and this yielded a large additional contact area between the sintered silver particles. This can be visualized with the help of the lower graph of Figure 3 and with Figures $6 \mathrm{~b}$ and $6 \mathrm{c}$.

\section{Outdoor tests of large modules}

Eight large modules with cell type of either quartered standard cells or QuarterCells $\mathrm{K}$ and different kinds of contact strips were produced and mounted with an inclination of about $10^{\circ}$ from vertical at a south west facade of the institute (Fig. 11). Unfortunately, QuarterCells P, to which the special connector (Fig. 6a) could be applied and which showed the best results with the small modules, were no longer available. As with the small mod- ules, the cells for the large modules were produced by Falconcell, except those of module M6, which used cells with 3 busbars cut from quadratic cells from Gintech. One module did not use contact strips, but its cells were connected by soldering with $\mathrm{SnPbAg}$-coated solder ribbon (M4). This module could serve as a reference, since it could be expected that the interconnetions would show little or no degradation. Cutting of cells and manufacturing of strings was done by the authors. Lamination and framing with aluminium profiles was done by the company PVT-Austria. Just as with almost all small modules the encapsulant was EVA. However the front glass was $4 \mathrm{~mm}$ thick hardened solar glass with random structured surface for reduced reflection and the back sheet was from a softer PE-based material and not the Tedlar of the small modules. The colour of the back sheets was black, except for the reference module M4, where it was white. As soon as a module was finished it was mounted on the stand. This is why they have different start dates and different periods of exposure until now. The operational cycle of the modules consisted in alternating open-circuit periods with short-circuit periods. Each of these periods lasted for several days to weeks. During the open-circuit periods current-voltage curves of each module were recorded every two minutes from sunrise to sunset. Table 3 gives an overview of the technical parameters of the modules.

The typical degradation of the current voltage curves over periods from 12 to 18 months are shown in Figure 12 for four different modules. The curves have been selected with the same short circuit current (1.2 A). Since for a given module the temperature of the initial curve and of the second curve from the later date were not the same, the open circuit voltages of the two curves to be compared were also different. Fortunately, this has only a small influence on the values of the fill factor, which are quoted in the figures. A recent review of theoretical temperature dependences is given in [39]. The expected temperature coefficient of the fill factor for crystalline silicon solar cells has been evaluated between -0.06 and $-0.09 \% / \mathrm{K}$ (percentage relative to the value of the fill factor) [40]. In practice, a temperature coefficient of $-0.19 \% / K$ has been found for a small module of two silicon solar cells connected in series [41]. This value has been adopted for the calculation of the temperature-corrected fill factor of the later date for each module, which is quoted in brackets in Figure 12. For these corrections the temperature coefficient of the open circuit voltage was also needed, and the field value of $-0.5 \% / \mathrm{K}$ obtained in [42] was used.

The essential information in Figure 12 is the change of slope of the IV-curve near the open circuit voltage. This section is more or less a straight line. The inverse of its slope has the dimension of resistance. Although this is not directly the series resistance, one can easily verify with the one- or two-diode model that a change of the series resistance of the module causes a numerically almost identical change of the inverse of this slope. Keeping this in mind, the changes in Figure 12 between initial and final curves show an increase in series resistance of all four modules and associated change in fill factor, although 
Table 3. Technical parameters of the eight large modules for outdoor measurements. "2BB": made from standard cells with 2 busbars. "3BB": made from standard cells with 3 busbars.

\begin{tabular}{ccccc}
\hline Module & $\begin{array}{c}\text { Number } \\
\text { of cells }\end{array}$ & Cell type & $\begin{array}{c}\text { Contact strips coating, } \\
T \times W[\mathrm{~mm}], \text { number }\end{array}$ & $\begin{array}{c}\text { Most similar } \\
\text { small module }\end{array}$ \\
\hline M1 & 252 & Standard, 2BB & $\mathrm{SnPbAg}, 0.20 \times 2.0,2$ & $\mathrm{~S} 2$ \\
M2 & 252 & Standard, 2BB & $\mathrm{Ag}, 0.19 \times 2.5,2$ & - \\
M3 & 252 & Standard, 2BB & $\mathrm{Ag}, 0.24 \times 2.5,2$ & - \\
M4 & 252 & Standard, 2BB & $\begin{array}{c}\text { Soldered reference } \\
0.10 \times 2.0,2\end{array}$ & - \\
M5 & 276 & QuarterCell K & $\mathrm{Ag}, 0.19 \times 5.0,4$ & $\mathrm{~K} 1, \mathrm{~K} 2$ \\
M6 & 252 & Standard, 3BB & $\mathrm{Ag}, 0.24 \times 2.5,3$ & - \\
M7 & 252 & Standard, 2BB & $\mathrm{Cu}, 0.20 \times 2.5,2$ & $\mathrm{~S} 3$ \\
M8 & 246 & QuarterCell K & $\mathrm{Ag}, 0.25 \times 5.0,3$ & $\mathrm{~K} 3$ \\
\hline
\end{tabular}
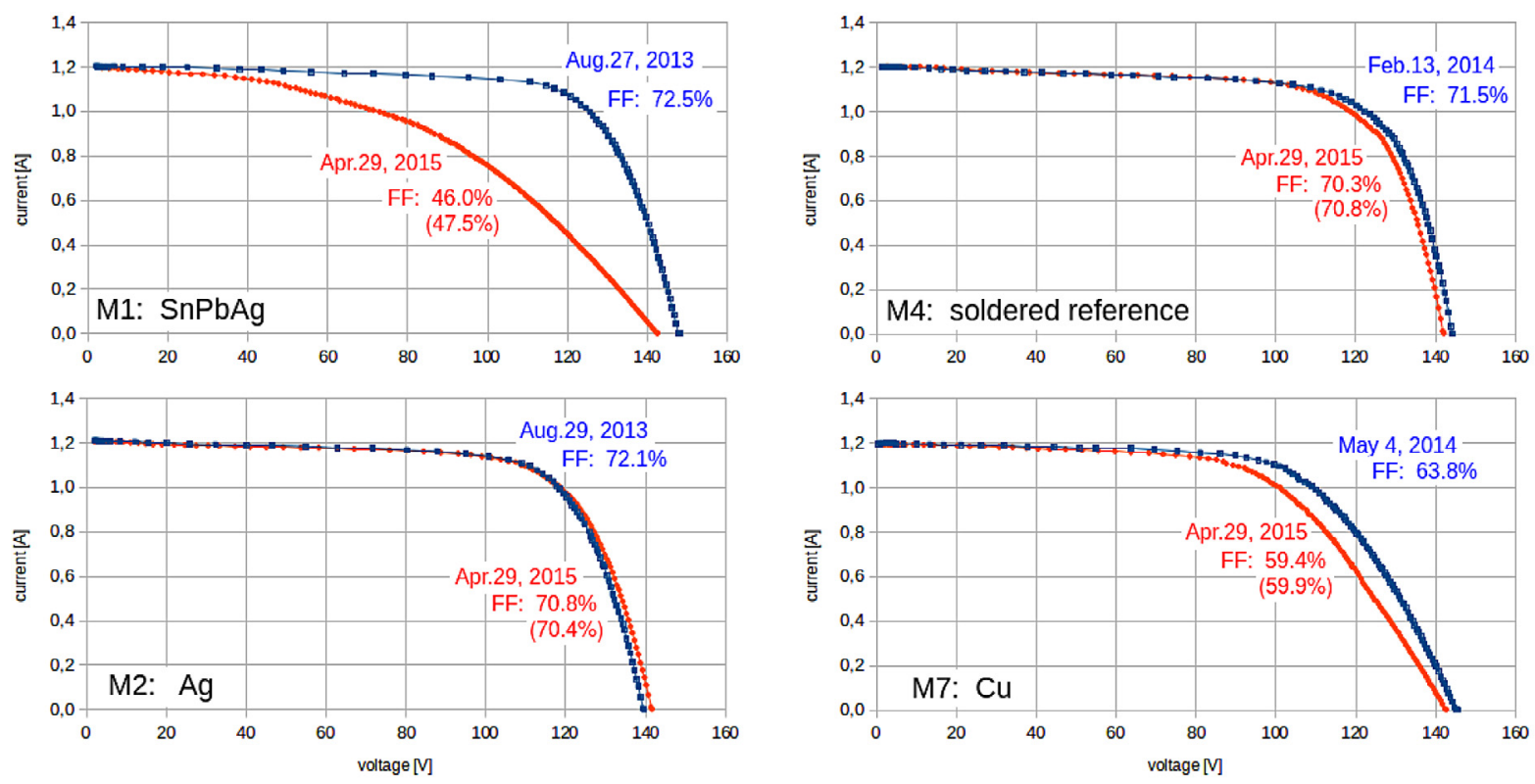

Fig. 12. IV-curves with short circuit current of $1.2 \mathrm{~A}$ for modules M1, M2, M4 and M7 at their first day in operation outdoors (blue) and after operation between 12 and 18 months (red). The different open circuit voltages of first and respective last day are almost solely due to different temperatures at the two days. For the later dates the measured fill factor (FF) and the fill factor corrected for the different temperature and different open circuit voltage are given (the latter one in brackets).

to quite a different degree, depending on the kind of cell interconnection. As could be expected from the results of the small modules, the module with $\mathrm{SnPbAg}$-coated contact strips (M1) showed the strongest deterioration of series resistance. Also the module with contact strips from pure $\mathrm{Cu}(\mathrm{M} 7)$ showed quite a considerable increase in series resistance. On the other hand, the module with Ag-coated contact strips (M2) suffered little deterioration. And so did the reference module (M4), for which hardly any deterioration was expected, because it had soldered cell interconnections.

Figure 13 gives an overview of the changes of the monthly averages of series resistance relative to the first month of operation of each module. The selection criteria of the IV-curves used for this analysis were a short circuit current between 1.4 and $1.5 \mathrm{~A}$ (but 1.3 and $1.4 \mathrm{~A}$ for module M5, because of the smaller illuminated area of each cell), a voltage at the maximum power point larger than $85 \mathrm{~V}$, and a fill factor larger than $40 \%$ (to elimi- nate data from partially shaded modules). These graphs confirm the relatively strong increase of series resistance for the module with $\mathrm{SnPgAg}$-coated contact strips (M1) and the more erratic behavior of the module with $\mathrm{Cu}-$ contact strips (M7), compared to the stable performance of the modules with Ag-coated contact strips. For these latter modules it can also be noted that there is a twelvemonth period of the changes of the series resistance. A closer inspection revealed a higher series resistance during the warm summer months. This agrees with the known change of series resistance of silicon solar cells [43] and the positive temperature coefficient of electrical resistance of metals.

As the outdoor modules virtually never work under conditions of STC, one has no direct information on how the changes of series resistance affect the nominal output power of the modules. Therefore the performance at STC was estimated in the following way: For each module, an IV-curve from the first few days with a short 
Table 4. Relative change of maximum power at STC normalized to one year ( $\Delta \mathrm{P} /$ year) estimated from outdoor IV data. For modules M1 to M7 data until Apr. 29, 2015 are included. For module M8 until Dec. 31, 2015, in order to cover a minimum of one year.

\begin{tabular}{|c|c|c|c|c|c|}
\hline Module & First day & $\begin{array}{c}\text { Contact } \\
\text { strip coating }\end{array}$ & $\begin{array}{c}\text { Maximum power } \\
\text { measured outdoor }[\mathrm{W}]\end{array}$ & $\begin{array}{c}\Delta P / \text { year } \\
{[\%]}\end{array}$ & $\begin{array}{l}\text { Decline of } \mathrm{FF} \\
{[\% \text { abs./year }]}\end{array}$ \\
\hline M1 & Aug. 23, 2013 & $\mathrm{SnPbAg}$ & 183.7 & -29.6 & -14.38 \\
\hline M2 & Aug. 29, 2013 & $\mathrm{Ag}$ & 226.5 & -2.4 & -1.28 \\
\hline M3 & Feb. 13, 2014 & $\mathrm{Ag}$ & 217.4 & -2.4 & -0.59 \\
\hline M4 & Feb. 13, 2014 & $\begin{array}{l}\text { soldered } \\
\text { reference }\end{array}$ & 215.7 & -2.5 & -1.26 \\
\hline M5 & Feb. 13, 2014 & $\mathrm{Ag}$ & 209.4 & -2.5 & -1.27 \\
\hline M6 & May 2, 2014 & $\mathrm{Ag}$ & 222.4 & +0.2 & -0.76 \\
\hline M7 & May 2, 2014 & $\mathrm{Cu}$ & 168.0 & -4.5 & -2.74 \\
\hline M8 & Sep. 4, 2014 & $\mathrm{Ag}$ & 204.4 & -2.5 & -1.99 \\
\hline
\end{tabular}
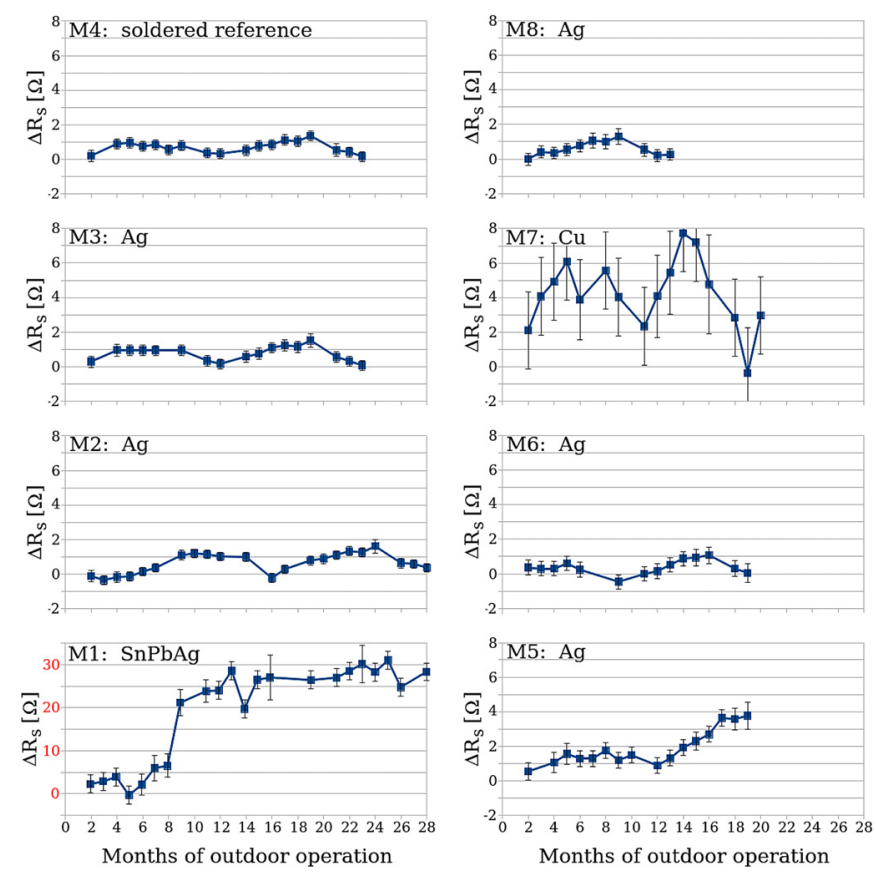

Fig. 13. Monthly averages of the change of series resistance $\left(\Delta R_{s}\right)$ relative to the first month of outdoor operation of each module. Extracted from IV-curves with short circuit current between 1.4 and 1.5 A (1.3 and 1.4 A for M5). Note the different scale for module M1.

circuit current around $1.2 \mathrm{~A}$ is selected and extrapolated to an IV-curve of same short circuit current, but with observed decline of the fill factor some 12 months up to about 18 months later (depending on module). This was done by fitting the IV-curve to the two diode model and then increasing the series resistance until the fill factor of the later point in time was reached. Then both curves were extrapolated to illumination of $1000 \mathrm{~W} / \mathrm{m}^{2}$, by changing the short circuit current to that known to apply at STC for that particular module. Then the maximum power of these curves could be compared, and the relative decrease in output power, normalized to the period of one year, could be calculated. The results are shown in Table 4 . This table also lists the maximum power which each module ever delivered outdoors. This was ususally around the

end of March, because with the given orientation and inclination, this is the time of year in which these modules can generate the highest power. The final column of Table 4 shows the decrease of the fill factor of each module, normalized to one year. The values are in absolute percent, not relative to the initial value. For this calculation the same selection criteria of IV-curves were used as for the data shown in Figure 13, especially because higher current was of interest (short circuit current between 1.4 and 1.5 A, (1.3-1.4 A for M5), because an increase of series resistance affects the fill factor more at higher currents, open circuit voltage larger $85 \mathrm{~V}$, fill factor larger $40 \%$ to eliminate partial shading of modules, which was possible for the lower modules M1, M2 and M5, M6 due to some bushes, especially in winter in the hours before sunset).

For the modules M1, M4, M6 and M7 the evolution of this fill factor is shown on a day-by-day basis in Figure 14. One notes the strong deterioration of module M1 due to its contact strips made from $\mathrm{SnPbAg}$. An actual jump of deterioration occurred during the short circuited period of March-April 2014. It is conceivable that during this period some contact strips became hot enough to melt and re-solidify their $\mathrm{SnPbAg}$ coating, which would first form good contact to the affected busbars of the cells, but upon cooling in the following night this would be broken again, leading to greater surface roughness and hence higher resistance (soldering would be unlikely, since there was no solder flux). Module M7, with its copper contact strips, also showed quite some deterioration, and it already started with a lower fill factor than other modules. This, and the relative magnitudes of fill factor decline of these two modules are in line with those found in the rapid ageing tests of the small modules with analogous contact strips (S2 and S3, respectively).

Interestingly, module M6, with Ag-coated contact strips shows a smaller decrease in fill factor than the soldered reference module M4. Two factors come into play here: on the one hand, there is some statistical error in the estimates of the decline of the fill factor, which should amount to less than $+-0.5 \%$ abs./year. On the other hand, module M6 was produced with cells from another company than all the other modules, and it already had the newer technology of three bus bars, which may 

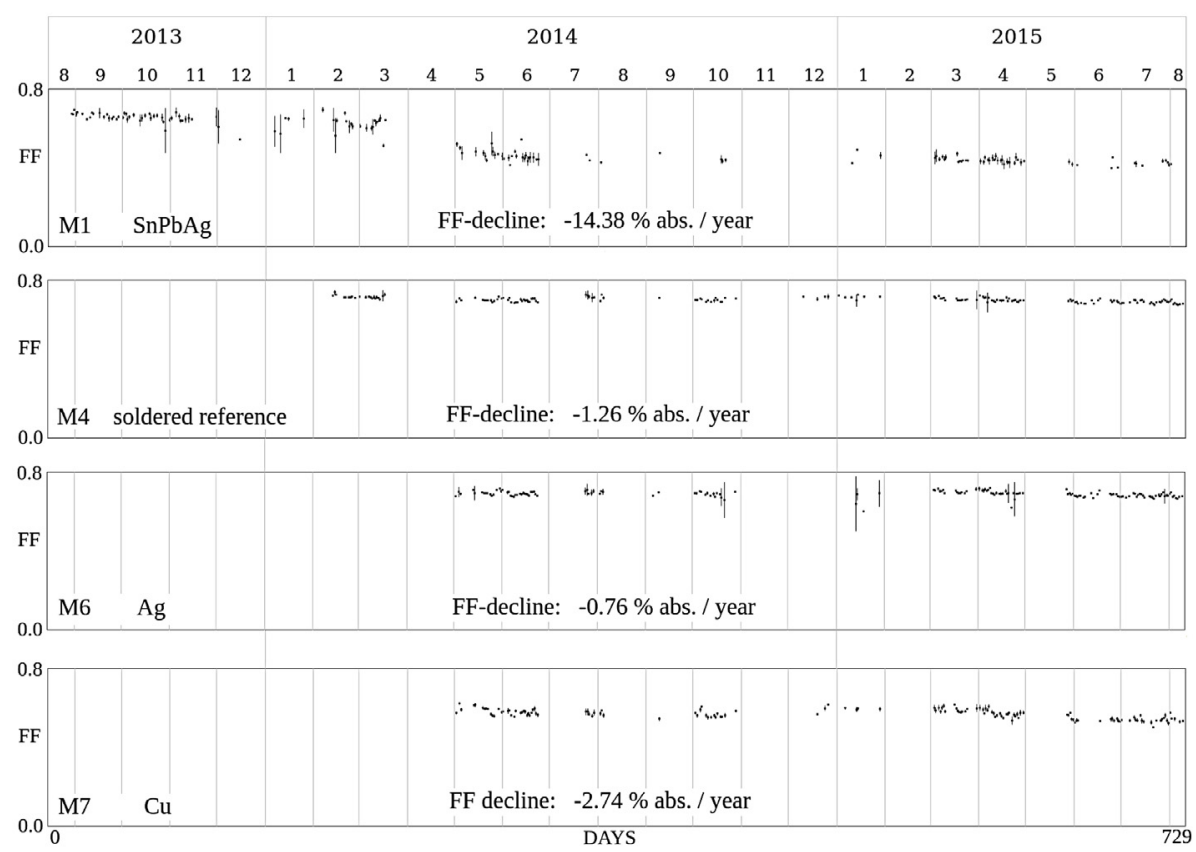

Fig. 14. Evolution of fill factor. Each data point represents the average of the fill factor of one day of the IV-curves with short circuit current between 1.4 and $1.5 \mathrm{~A}$, a voltage at the maximum power point larger than $85 \mathrm{~V}$, and a fill factor larger than $40 \%$. The vertical bars indicate the standard deviation.

be an indication, that the silicon used in these cells or the screen printed metallization was of higher quality, too. This opens the possibility that the decline of fill factor of the reference module M4 may not be due to an increase of series resistance of the soldered cell interconnections, but to other ageing effects of the cells [44-46].

In Table 4 it should also be noted that module M8 showed a tendency towards a larger decline of fill factor, although its contact strips were silver coated. This module used the same interconnection scheme as the small module K3 (see Figs. 5c and 5d), which means that on the back sides of the cells the contact strips were pressed onto the cells only by the adhesive tape, the encapsulant, and the back sheet of the module. Most likely this pressure is quite a bit lower than that exerted on a contact strip between two overlapped cells, and it may get smaller with repeated warming and cooling of the module, due to a change of viscoelastic properties of EVA $[27,32,33]$.

\section{Summary and conclusion}

Comparing the results of rapid ageing of the small modules by thermal cycling and the slower ageing by outdoor exposure of the large modules, one notes that with respect to the different coating materials of the contact strips they show the same trends: Modules with $\mathrm{SnPbAg}$ coated contact strips quickly accumulate a high series resistance in both cases, modules with pure $\mathrm{Cu}$ contact strips show less degradation, but it is still unacceptably high. Also the one small module with Sn-coated contact strips showed a high loss in power after only a few hundred cycles, although it performed better than the modules with pure $\mathrm{Cu}$ contact strips. Only the modules with
Ag-coated contact strips exhibit high reliability and appear to degrade no faster than modules with soldered cell interconnections. One large module with Ag-coated contact strips showed an even slower decline of fill factor than the soldered reference module, but possibly this must be attributed to its cell quality. On the other hand it underlines the quality of its contact strips.

Of the three different types of polycrystalline cells employed in this investigation - quartered standard cells, and the special QuarterCells of type K and P, respectively the type QuarterCell $\mathrm{P}$ performed best. The reason is that its metallization pattern on front and back side was optimally laid out for cell overlap of $2 \mathrm{~mm}$, and maximum contact area between any two cells was achieved.

An interesting observation on small modules with Agcoated contact strips was that after the initial thermal cycles their series resistance became smaller before it started the expected slow increase. This feature is as yet unexplained but a combination of changing of the properties of EVA in a kind of post processing during thermal cycling [33], and a better adaptation of the silver coating of the contact strips to the grainy surface of the screen printed bus bars on the cells seem plausible.

Another open question is how frequently micro cracks will occur in the bent regions of the cells. This will depend on the curvature imposed on the cell, which in turn will depend on the thickness of the contact strips and their spacing. Micro cracks need not have a noticeable effect on the power output of the module [18], but in time they may develop into real cracks which separate a part of a cell electrically from the rest. A first check has been done with an electroluminescence scan on one of the worst performing small modules (S2), and it did indeed reveal a 
small crack at a position of a contact strip [47]. However, the performance of the large modules, with as many as 276 cells connected in series, and especially that of the small modules with cell type QuarterCell $\mathrm{P}$ and special connector, indicates that micro cracks may be a minor issue.

A final remark concerns the potential savings of PV modules with crystalline silicon solar cells made with cell interconnections solely based on contact pressure. As we have shown, the overlap concept alone permits more than $6 \%$ higher power density of a module without changing the cell technology. And if pressure based contact strips are used instead of the traditional soldering or glueing of metallic ribbons, only very little metal is needed for the cell interconnections. We estimate that between $70 \%$ and $90 \%$ of the copper currently needed in a typical module with 60 quadratic cells of $156 \times 156 \mathrm{~mm}$ can be saved in a module of the same power but made with the kind of cells and interconnections presented here. Therefore, although the overlap concept requires a few percent more silicon, the overall material savings and the higher power density should make it an economically more attractive option.

We would like to thank J.L. Lang for development and mechanical measurements on the interconnections of the small modules during the starting phase of the project. We are also grateful to Prof. Marko Topic and Dr. Kristijan Brecl from the University of Lubljana in Slovenia for a first electroluminescence scan of a small module.

\section{References}

1. J. John, V. Prajapati, B. Vermang, A. Lorenz, C. Allebe, A. Rothschild, L. Tous, A. Uruena, K. Baert, J. Poortmans, EPJ Photovolt. 3, 35005 (2012)

2. Z. Halavani, J.L. Lang, J. Summhammer, Results of Pressure-Only Cell Interconnections in High Voltage PVModules, in 29th EUPVSEC, Amsterdam, 2014, p. 64

3. J. Summhammer, Z. Halavani, High-Voltage PV- Modules with Crystalline Silicon Solar Cells, in 28th EUPVSEC, Paris, 2013, p. 3119

4. J. Schneider, S. Schönfelder, S. Dietrich, M. Turek, Solar Module with Half Size Solar Cells, in 29th EUPVSEC, Amsterdam, 2014, p. 185

5. E. Franklin, A. Blakers, K. Weber, V. Everet, Sliver Solar Cell Technology: Pushing the Material Boundaries, in MRS Proceedings, 2011, p. 1323

6. E. Franklin, V. Everett, A. Blakers, K. Weber, Adv. Optoelectron. 2007, 35383 (2007)

7. R. Ebner, M. Schwark, G. Újvári, W. Mühleisen, C. Hirschl, L. Neumaier, M. Pedevilla, J. Scheurer, A. Plösch, A. Kogler, W. Krumlacher, H. Muckenhuber, Increased Power Output Of Crystalline Silicon Solar Modules By Application Of New Module Concepts, in 29th EUPVSEC, Amsterdam, 2014, p. 171

8. A. Schneider, R. Harney, S. Aulehla, S. Hummel, E. Lemp, S. Koch, K. Schröder, Conductive Gluing as Interconnection Technique towards Solar Cells without Front Busbars and Rear Pads, in 27th EUPVSEC, 2012, p. 335
9. G. Beaucarne, I. Kuzma-Filipek, F. Campeol, X. Young, J. Wei, Y. Yu, R. Russell, F. Duerinckx, Energy Procedia 67, 185 (2015)

10. J. Dupuis, E. Saint-Sernin, P. Lefillastre, A. Vachez, E. Pilat, D. Bussery, R. Einhaus, Cell-ribbons contacts interface study in NICE modules, in 26th EUPVSEC, Hamburg, 2011, p. 3117

11. O. Nichiporuk, J. Dupuis, E. Saint-Sernin, J. Degoulange, P. Lefillastre, R. Einhaus, Secured Intrinsic UnderPressure in the NICE Modules - The Oxygen Gettering Approach, in 27th EUPVSEC, 2012, p. 3449

12. J. Summhammer, H. Rothen, Rectangular silicon solar cell with more power and higher voltage modules, in 24 th EUPVSEC, Hamburg, 2009, p. 2221

13. US Patent in 1966, http://www.google.com/patents/ US3459597 and in 1972, http://www.google.com/patents/ US3769091

14. Electrical contacts: principles and applications, edited by P.G. Slade (Marcel Dekker Inc. New York, 1999). Especially Chap. 1.2 and 1.3

15. N. Bogdanski, W. Herrmann, Weighting of Climatic Impacts on PV-Module Degradation - Comparison of Outdoor Weathering Data and Indoor Weathering Data, in 26th EUPVSEC, Hamburg, 2011, p. 3093

16. P. Hülsmann, M. Heck, M. Köhl, J. Mater. 2013, 102691 (2013)

17. K.R. McIntosh, J.N. Cotsell, J.S. Cumpston, A.W. Norris, N.E Powell, B.M. Ketola, The effect of accelerated aging tests on the optical properties of silicone and EVA encapsulants, in 24th EUPVSEC, Hamburg, 2009, p. 3475

18. T.M. Pletzer, J.I. Van Mölken, S. Rißland, O. Breitenstein, J. Knoch, Prog. Photovolt.: Res. Appl. 23, 428 (2015)

19. Review of Failures of Photovoltaic Modules, Report IEAPVPS T13-01:2014. Available at: http://iea-pvps.org/ index.php?id $=275$

20. U. Eitner, M. Koentges, R. Brendel, Measuring Thermodynamical Displacements of Solar Cells in Laminates Using Digital Image Correlation, in Proceedings of 34th IEEE PVSEC, Philadelphia, 2009, pp. 1280-1284

21. U. Eitner, M. Köntges, R. Brendel, Sol. Energy Mater. Sol. Cells 94, 1346 (2010)

22. www.engineeringtoolbox.com/ linear-expansion-coefficients-d_95.htm

23. C.A. Swenson, J. Phys. Chem. Ref. Data 12, 179 (1983)

24. http://www.dupont.com/content/dam/dupont/ products-and-services/membranes-and-films/pvf-films/ documents/DEC_Tedlar_GeneralProperties.pdf

25. M. Paggi, S. Kajari-Schröder, U. Eitner, J. Strain Anal. Eng. Design 46, 772 (2011)

26. M. Schmidt, P. Guttmann, K. Berger, Y. Voronko, M. Knausz, G. Oreski, G. Eder, T. Koch, G. Pinter, Polymer Testing 44, 160 (2015)

27. U. Eitner, M. Pander, S. Kajari-Schröder, M. Köntges, H. Altenbach, Thermomechanics of PV Modules Including the Viscoelasticity of EVA, in 26th EUPVSEC, Hamburg, 2011, p. 3267

28. M.D. Kempe, G.J. Jorgensen, K.M. Terwilliger, T.J. McMahon, C.E. Kennedy, T.T. Borek, Ethylene-Vinyl Acetate Potential Problems for Photovoltaic Packaging, in Conference Record of the 2006 IEEE 4th World Conference on Photovoltaic Energy Conversion, 2006, Vol. 2, pp. 2160-2163 
29. A.A. Ogwu, T.H. Darma, E. Bouquerel, J. Achiev. Mater. Manuf. Eng. 24/1, 172 (2007)

30. T. Suehiro, T. Sasaki, Y. Hiratate, Thin Solid Films 383, $318(2001)$

31. L. De Los Santos Valladares, D. Hurtado Salinas, A. Bustamante Dominguez, D. Acosta Najarro, S.I Khondaker, T. Mitrelias, C.H.W. Barnes, J. Albino Aguiar, Y. Majima, Thin Solid Films 520, 6368 (2012)

32. D. Wu, J. Zhu, D. Montiel Chicharro, T.R. Betts, R. Gottschalg, Influences of Different Lamination Conditions on the Reliability of Encapsulation of PV Modules, in 29th EUPVSEC Amsterdam, 2014, p. 3415

33. C. Hirschl, L. Neumaier, W. Mühleisen, M. DeBiasio, G. Oreski, A. Rauschenbach, G.C. Eder, B.S. Chernev, M. Kraft, Post-Crosslinking in Photovoltaic Modules under Different Conditions, in 29th EUPVSEC Amsterdam, 2014, p. 3133

34. J. Song, L. Wang, A. Zibart, C. Koch, Metals 2, 450 (2012)

35. A. De Rooij, ESA J. 13, 363 (1989)

36. P. Narayana Reddy, M. Hari Prasad Reddy, J.F. Pierson, S. Uthanna, ISRN Optics 2014, 684317 (2014)

37. http://www.chemicool.com/elements/silver.html

38. M.M. El-Nahass, A.A.M. Farag, E.M. Ibrahim, S. Abd-ElRahman, Vacuum 72, 453 (2004)
39. O. Dupré, R. Vaillon, M.A. Green, Sol. Energy Mater. Sol. Cells 140, 92 (2015)

40. P. Singh, N.M. Ravindra, Sol. Energy Mater. Sol. Cells 101, 36 (2012)

41. S. Chander, A. Purohit, A. Sharma, S.P. Nehra, M.S. Dhaka, Energy Rep. 1, 175 (2015)

42. P. Kamkird, N. Ketjoy, W. Rakwichian, S. Sukchai, Procedia Eng. 32, 376 (2012)

43. S. Bensalem, M. Chegaar, Revue des Energies Renouvelables 16, 171 (2013)

44. C.R. Osterwald, J. Pruett, T. Moriarty, Crystalline silicon short circuit current degradation study: initial results, in Conference Record of the 31st IEEE Photovoltaic Specialists Conference, Lake Buena Vista, FL, 2005, pp. $1335-1338$

45. C. Peike, S. Hoffmann, P. Hülsmann, B. Thaidijsmann, K.A. Weiß, M. Koehl, P. Bentz, Sol. Energy Mater. Sol. Cells 116, 49 (2013)

46. N.C. Park, W.W. Oh, D.H. Kim, Int. J. Photoenergy 2013, 925280 (2013)

47. M. Topic, University of Lubljana, customer measurement report, June 2015 (unpublished)

Cite this article as: Johann Summhammer, Zahra Halavani, Cell interconnection without glueing or soldering for crystalline Si photovoltaic modules, EPJ Photovoltaics 7, 75401 (2016). 